\title{
Robótica Sustentável: Explorando a criatividade e a conscientização ambiental no Ensino Fundamental
}

\author{
Dayane R. de Souza ${ }^{1}$, Genarde M. Trindade ${ }^{1}$, Luiz Sérgio de O. Barbosa ${ }^{1}$ \\ ${ }^{1}$ Centro de Estudos Superiores de Itacoatiara (CESIT) - Universidade do Estado do \\ Amazonas (UEA) - Itacoatiara - AM - Brasil \\ dayanerosas@gmail.com, genardemacedo@gmail.com, lsergio@uea.edu.br
}

\begin{abstract}
Sustainable Robotics allows students to develop hypotheses, investigate solutions, build relationships and draw conclusions. The use of electronic waste and recycled materials in the construction of robot prototypes not only aims to reduce costs, but is also an alternative to recycle these wastes that would often be discarded incorrectly in the environment. Thus, this research presents the proposal for the implementation of Sustainable Robotics activities in a public elementary school in the municipality of Itacoatiara/AM. It is hoped to explore the students' creativity, cooperative work and the importance of environmental awareness.
\end{abstract}

Resumo. A Robótica Sustentável permite que estudantes possam elaborar hipóteses, investigar soluções, estabelecer relações e tirar conclusões. A utilização de lixo eletrônico e materiais reciclados na construção de protótipos de robôs visam não só baratear os custos, mas também é uma alternativa para reciclagem desses resíduos que seriam descartados muitas das vezes de forma incorreta no meio ambiente. Assim, esta pesquisa apresenta a proposta de implementação de atividades de Robótica Sustentável em uma escola pública de Ensino Fundamental no municipio de Itacoatiara/AM. Espera-se explorar a criatividade dos estudantes, o trabalho cooperativo e a importância da conscientização ambiental.

\section{Introdução}

Vivemos em uma sociedade onde ter competência na utilização de tecnologias e no desenvolvimento de atividades em grupo são essenciais para o desenvolvimento cognitivo [Almeida, Netto, Custódio, 2017]. Neste contexto, a Robótica Sustentável objetiva contribuir de forma eficaz no desenvolvimento destas competências. Além disso, pode ser um espaço rico de possibilidades do desenvolvimento de habilidades, da criatividade e da conscientização ambiental do aluno [Albuquerque et al., 2017].

A escola tem se empenhado em atender as necessidades resultantes das mudanças que ocorrem na sociedade, por meio da aplicação de metodologias que valorizam o aprender pelo fazer, a compreensão e não apenas a assimilação de conteúdos [Avila et al., 2017]. A oferta de recursos tecnológicos adequados aos processos de ensino aprendizagem são meios importantes para a formação do cidadão, nessa que é denominada sociedade do conhecimento [Santos e Medeiros, 2017; Dias, Abdalla, Saba, 2017]. 
VIII Congresso Brasileiro de Informática na Educação (CBIE 2019)

Anais do XXV Workshop de Informática na Escola (WIE 2019)

A inserção de recursos tecnológicos como apoio na educação é um dos grandes debates abertos no Brasil. Em países de primeiro mundo esse assunto já foi superado, pois a maioria da população já tem acesso a recursos como computador, internet e programas educativos na escola e em casa [Costa et al., 2017]. Por outro lado, a realidade brasileira, mais especificamente, em escolas públicas, aponta para o uso intenso de soluções livres, abrindo assim um campo interessante para a utilização de lixo eletrônico e materiais reciclados [Bogarim, Larrea, Ghinozzi, 2015].

Assim, a pergunta que norteia este estudo é "Como podemos reaproveitar o lixo eletrônico e materiais reciclados de maneira pedagógica para a construção de um ambiente de aprendizagem, de forma que promova impactos educacionais na sociedade?". Baseado nessa questão problema, o objetivo deste estudo é aplicar a Robótica Sustentável em uma escola de Ensino Fundamental no município de Itacoatiara/AM, visando explorar a criatividades dos alunos na produção de protótipos de robôs, além de contribuir com a conscientização ambiental.

\section{Robótica Sustentável}

A Robótica Sustentável está baseada em três pilares: Educação, sustentabilidade e inclusão social. Ao mesmo tempo em que prezamos pelo uso de materiais recicláveis na composição dos objetos, desenvolvendo a consciência ambiental e ecológica dos estudantes, não abrimos mão da produção de baixo custo, fazendo com que o acesso à tecnologia seja possível a todos [Albuquerque et al., 2017].

Estudos realizados por vários pesquisadores como Albuquerque et al. (2017), Bogarim (2015), Bogarim, Larrea, Ghinozzi (2015), Santos, Medeiros (2017), Silva et al., (2018), entre outros, demonstram que atividades com Robótica Sustentável propiciam meios para que o estudante formule hipóteses relacionadas ao seu objeto de investigação, explore ideias que o levem a discutir e colocar em prática a sua própria maneira de pensar, validar resultados e construir argumentos que possam ser aplicados.

Assim, a Robótica Sustentável promove um ambiente constituído de materiais de baixo custo, como lixo eletrônico e materiais reciclados, onde o aprendiz, por meio da integração destes materiais, constrói soluções para a produção de peças que resultarão em protótipos de robô funcional [Bogarim, 2015]. Pois, a construção protótipos de robô tem sido utilizada para desenvolver temas como a representação de símbolos e valores, e evocar a reflexão sobre a aprendizagem cooperativa entre grupos de estudantes [Vieira, Costa, Gadelha, 2018].

\section{Trabalhos Relacionados}

Com base na revisão bibliográfica, a seguir são apresentadas algumas pesquisas científicas que serviram como suporte para a realização deste estudo. São elas: Albuquerque et al. (2017), Bogarim (2015) e Silva et al. (2018).

O trabalho de Albuquerque et al. (2017) intitulado, "Robô Eco-Sustentável para aplicação em robótica educativa, utilizando lixo tecnológico". Os autores indagam que no mundo contemporâneo os alunos buscam interatividade, porém nas escolas tradicionais as práticas pedagógicas sofrem com as limitações relacionadas ao confinamento teórico. A pesquisa ressaltada a importância de serem testados novos 
VIII Congresso Brasileiro de Informática na Educação (CBIE 2019)

Anais do XXV Workshop de Informática na Escola (WIE 2019)

instrumentos didáticos, como os kits de robótica educacional. Pois, de acordo com os autores a utilização da robótica como instrumento de ensino permite aos estudantes a capacidade de elaborar hipóteses, investigar soluções, estabelecer relações e tirar conclusões. $\mathrm{O}$ objetivo principal da pesquisa era utilizar o lixo eletrônico na construção do kit robô eco-sustentável, visando não só baratear os custos, mas também como uma alternativa para reciclagem desse resíduo.

A pesquisa de Bogarim (2015), intitulada "Laboratório de Robótica Sustentável (LarPP Sustentável)”, propõe a comunidade local Ponta Porã/MS o descarte consciente dos lixos eletrônicos, para que possam ser empregados em projetos de robótica no campus da Universidade Federal de Mato Grosso do Sul que fica situado no município, reduzindo os custos operacionais e o impacto ambiental de suas atividades. Além disso, a pesquisa visou reutilizar componentes de computadores descartados para oferecer manutenção em computadores de escolas públicas do município para evitar que estes sejam descartados, diminuindo o custo das escolas. Os autores informam que ministraram uma série de palestras nestas escolas sobre a gravidade do lixo eletrônico para a saúde e a natureza, e orientando-os ao descarte consciente.

O trabalho de Silva et al. (2018) foi intitulado, "Storytelling e Robótica Educacional: a construção de carros robôs com Arduino e materiais recicláveis". Os autores relatam que o trabalho trata-se de uma experiência de ensino, em que, usaram a plataforma Arduino e materiais recicláveis na construção carros robôs de futebol seguindo a contextualização de uma narrativa. Assim, de acordo com os idealizadores da pesquisa foi possível observar que o desenvolvimento de uma história constrói um significado aos alunos para guiá-los na produção, além de prover ludicidade. Dessa forma, os autores concluíram que os alunos sentiram-se mais interessados e motivados em aprender os conceitos de programação e em construir os carros robôs de uma forma lúdica, além que transmitir a importância de utilizar materiais reciclados.

De acordo com as leituras e as informações coletadas nos trabalhos científicos que ajudaram a fomentar esta proposta de estudo, nota-se a importância de promover ações que enfatizam na reutilização ou reaproveitamento de lixo eletrônico e materiais reciclados. Desta forma, este trabalho visa explorar a criatividade de alunos do Ensino Fundamental de uma escola no município de Itacoatiara/AM, sendo empregada a Robótica Sustentável para o desenvolvimento de protótipos de robô, a resolução de problemas em equipe e na construção da conscientização ambiental dos alunos.

\section{Procedimentos Metodológicos}

A metodologia empregada na pesquisa é de caráter experimental com abordagem qualitativa. Possui cinco etapas, sendo: (1) Revisão Bibliográfica; (2) Planejamento do Estudo; (3) Execução do Estudo; (4) Estudo de Observação e (5) Análise dos Resultados. A seguir serão apresentadas as etapas da metodologia e como foram executadas.

Revisão Bibliográfica: Nesta etapa foram realizadas buscas de artigos científicos que possuem características com a proposta do estudo no Google Scholar e em anais dos principais eventos nacionais na área de Informática na Educação, promovidos com o apoio da Sociedade Brasileira de Computação (SBC). Por meio da submissão de palavras-chave utilizando buscas avançadas. O idioma escolhido foi o Português, por 
VIII Congresso Brasileiro de Informática na Educação (CBIE 2019)

Anais do XXV Workshop de Informática na Escola (WIE 2019)

ser adotado pela grande maioria das conferências, periódicos e editoras nacionais relacionadas com tema da pesquisa listadas no Portal de Periódicos da CAPES. Dessa forma, às palavras-chave utilizadas para a busca do material científico foram: Robótica Educacional, Sustentável, Material Reciclado, Lixo Eletrônico, Baixo Custo e Conscientização Ambiental. Durante as buscas setenta e cinco trabalhos foram encontrados, realizando um breve skimming, somente quinze artigos foram considerados mais relevantes e dez artigos foram considerados importantes para embasar o estudo.

Planejamento do Estudo: Realizou-se a construção do cronograma com as atividades estabelecidas como primordiais para a execução do estudo. Dentre elas estão: Definição do local para realização do estudo; Autorização para participação dos alunos; Definição do tempo de duração do estudo; Organização e elaboração das Tarefas/Desafios; Caracterização do participante; Elaboração do questionário pós-teste; Estudo de observação.

Execução do Estudo: Serão executadas as atividades definidas no planejamento do estudo, respeitando cronograma de atividades.

Estudo de Observação: Propor uma análise detalhada sobre o impacto que o estudo com os alunos, notar fatores de ganho de habilidade, relacionamento interpessoal, soluções de problemas e outros aspectos pertinentes ao estudo.

Análise dos Resultados: Após a coleta dos dados será realizada a análise dos resultados dos questionários pós-teste respondidos e do estudo de observação. Dessa forma, analisando qualitativamente os dados para que seja possível a mensuração e apresentação dos resultados do estudo.

\section{Considerações Finais e Resultados Esperados}

Este artigo apresenta a proposta de estudo de utilização da Robótica Sustentável para explorar ações criativas na produção de protótipos de robôs com estudantes do Ensino Fundamental no município de Itacoatiara/AM, por meio do uso de lixo eletrônico e materiais reciclados para promover a conscientização ambiental. Além de trabalhar junto à comunidade escolar local para mostrar a importância da conscientização ambiental e a reutilização de lixo eletrônico bem como de materiais reciclados e Promover oficinas para exposição dos protótipos de robô.

Como resultado esperado para este estudo, pretende-se: (1) Desenvolver protótipos de robôs funcionais, como a utilização de material de baixo custo; (2) Colaborar com a comunidade acadêmica e a sociedade em geral, levantando o tema a importância da educação ambiental as escolas da rede pública do munícipio; (3) Proporcionar aos participantes do projeto experiências de resolução de problemas e trabalho em equipe; (4) Elaborar um artigo sobre o estudo, a fim de submeter em eventos da área de informática na educação para que seja socializado e possa ganhar mais visibilidade; e (5) Criar uma base de conhecimento com a utilização da Robótica Sustentável na educação para trabalhos futuros. 
VIII Congresso Brasileiro de Informática na Educação (CBIE 2019)

Anais do XXV Workshop de Informática na Escola (WIE 2019)

\section{Agradecimentos}

Nossos agradecimentos a Pró-Reitoria de Extensão e Assuntos Comunitários (PROEX) da Universidade do Estado do Amazonas (UEA) e aos acadêmicos do curso de Licenciatura em Computação do Centro de Estudos superiores de Itacoatiara (CESIT), Valéria Grana Nogueira e Felipe Martins do Nascimento.

\section{Referências}

Albuquerque, M. F. A. et al. (2017). Robô Eco-Sustentável para aplicação em robótica educativa utilizando lixo tecnológico. Caderno de Graduação-Ciências Exatas e Tecnológicas-UNIT-ALAGOAS.

Almeida, T.; Netto, J. F.; Custódio, T. (2017). Desenvolvimento e Configuração de Cenários de Robótica para Fomentar a Aprendizagem de Programação aos Alunos do Ensino Fundamental. In: Anais do Workshop de Informática na Escola.

Avila, C. et al. (2017). Programação e robótica na escola: aplicação de roteiros e instrumentos avaliativos em um projeto piloto. In: Anais do Workshop de Informática na Escola.

Bogarim, C. A. C. et al. (2015). Laboratório de Robótica Sustentável (LarPP Sustentável). VI Escola Regional de Informática, Coxim-MT.

Bogarim, C. A. C.; Larrea, A. A.; Ghinozzi, G. G. (2015). Larpp Sustentável e seu Auxílio na Educação Ambiental nas Escolas e Comunidade de Ponta Porã. In: II Congresso Nacional de Educação, Campina Grande-PB.

Costa, T. et al. (2017). O Ensino de Linguagem de Programação na Educação Básica Através da Robótica Educacional: Práticas e a Interdisciplinaridade. In: Anais do Workshop de Informática na Escola.

Dias, J.; Abdalla, D.; Saba, H. (2017). Clube de Robótica: autonomia e protagonismo juvenil por meio de atividade complementar na escola. In: Anais do Workshop de Informática na Escola.

Santos, I.; Medeiros, L. F. (2017). Robótica com Materiais Recicláveis e a Aprendizagem Significativa no Ensino da Matemática: Estudo Experimental no Ensino Fundamental. In: Anais do Workshop de Informática na Escola.

Silva, J. et al. (2018). Storytelling e Robótica Educacional: a construção de carros robôs com Arduino e materiais recicláveis. In: Brazilian Symposium on Computers in Education (Simpósio Brasileiro de Informática na Educação-SBIE).

Vieira, V.; Costa, A.; Gadelha, B. (2018). Comparando as opiniões do professor e seus alunos sobre o uso de um laboratório virtual de robótica: um relato de experiência. In: Anais do Workshop de Informática na Escola. 